\title{
Subacute (28 day) Toxicity of Surfactin C, a Lipopeptide Produced by Bacillus subtilis, in Rats
}

\author{
Youn-Hwan Hwang, ${ }^{a, c}$ Myoung-Seok Kim, ${ }^{a, c}$ In-Bae Song, ${ }^{a, c}$ Byung-Kwon Park, ${ }^{c}$ \\ Jong-Hwan Lim, ${ }^{d}$ Seung-Chun Park, ${ }^{e}$ and Hyo-In Yun ${ }^{*}, a, b$ \\ ${ }^{a}$ College of Veterinary Medicine, Chungnam National University, 220 Gung-dong, Yuseong-gu, Daejeon 305-764, Republic of Korea, \\ ${ }^{b}$ Institute of Veterinary Science, Chungnam National University, 220 Gung-dong, Yuseong-gu, Daejeon 305-764, Republic of Korea, \\ c JUNJINBIO, 711 Hoam-dong, Dalseo-gu, Daegu 704-230, Republic of Korea, ${ }^{d}$ B\&C Biopharm, 633-2 Goan, Youngin, Gyeonggi-do \\ 449-863, Republic of Korea and ${ }^{e}$ College of Veterinary Medicine, Kyungpook National University, 1370 Sankyuk-dong, Buk-gu, Daegu \\ 702-701, Republic of Korea
}

(Received June 16, 2008; Accepted March 2, 2009)

\begin{abstract}
Surfactin C, produced by acillus subtilis isolated from Korean soybean paste, was given to Sprague-Dawley rats of both sexes at dose of 500, 1000 or $2000 \mathrm{mg} / \mathrm{kg}$ for 28 days. There were no surfactin C-related toxicities in survival, clinical signs, and hematological parameters in the experimental period. The highest dose of surfactin $\mathrm{C}$ showed the decrease in body weight gain despite normal food and water consumptions and the increase in relative liver weight. alanine aminotransferase (ALT), aspartate aminotransferase (AST) and alkaline phosphatase (ALP) levels were increased in animals administered with surfactin C of 1000 or $2000 \mathrm{mg} / \mathrm{kg}$. Zonal necrosis of hepatocyte around the hepatic vein was observed after administration of the same doses in a dose-dependent manner. In the present study, the no-observed-adverse-effect level (NOAEL) of surfactin C was $500 \mathrm{mg} / \mathrm{kg}$ following oral administration in rats.
\end{abstract}

Key words — subacute toxicity, surfactin C, no-observed-adverse-effect level, rats

\section{INTRODUCTION}

Biosurfactants originated from microorganisms have several advantages as replacements of chemical surfactants, including lower production cost, less toxicity, higher biodegradability and effectiveness at extreme temperatures or $\mathrm{pH}$ values. ${ }^{1,2)} \mathrm{Re}-$ cently, many researchers have investigated on the potential applications of biosurfactants for the food, cosmetic and pharmaceutical industries. ${ }^{3,4)}$

Surfactins produced by Bacillus subtilis are well-known as powerful antimicrobial lipopeptides on the bacteria, fungi and virus. ${ }^{5-7)}$ In addition, the lipopeptides have antitumor, fibrinolytic and anti-inflammatory activities. ${ }^{8-10)}$ The surfactin isomers are classified into three types, surfactin A, $\mathrm{B}$ and $\mathrm{C}$, based on differences of their amino acid sequences. ${ }^{11,12)}$ In the previous study, we isolated Bacillus subtilis BC1212 from Korean soy-

*To whom correspondence should be addressed: College of Veterinary Medicine, Chungnam National University, 220 Gung-dong, Yuseong-gu, Daejeon 305-764, Republic of Korea. Tel.: +82-42-821-6759; Fax: +82-42-822-5780; E-mail: hiyun@cnu.ac.kr bean paste. Surfactin $\mathrm{C}$ was the major component of surfactin isomers. ${ }^{13)}$ Kikuchi and Hasumi reported that surfactin $\mathrm{C}$ enhanced fibrin degradation through both prourokinase (pro-u-PA)/plasminogen and two-chain urokinase (tcu-PA)/plasminogen systems. ${ }^{14)}$ Recently, it inhibited the overproduction of tumor necrosis factor and nitric oxide induced by lipopolysaccharide in rats. ${ }^{15)}$

Despite biological beneficial activities of surfactin $\mathrm{C}$, there are no available toxicity data that allow the establishment of a no-observed-adverseeffect level (NOAEL). In the preliminary study, surfactin $\mathrm{C}$ did not show any toxicological effects at dose of $2500 \mathrm{mg} / \mathrm{kg}$ after single oral administration. This study was performed to evaluate subacute toxicity of surfactin $\mathrm{C}$ in Sprague-Dawley rats, being the highest dose of srufactin C $2000 \mathrm{mg} / \mathrm{kg}$.

\section{MATERIALS AND METHODS}

Animals — Adult Sprague-Dawley rats of either sex, aged 6-8 weeks with weights of 180-220 g were purchased from Samtaco (Osan, Republic of 
Korea) and acclimatized for 1 week. The animals were randomly assigned into three groups and kept five per stainless steel cage with $12 \mathrm{hr}$ light/dark cycle in a temperature $\left(22 \pm 1^{\circ} \mathrm{C}\right)$ and humidity $(50 \pm 2 \%)$ controlled environment. They were provided with food and water ad libitum during the experimental period. This study was approved by the Animal Care Committee of Chungnam National University (Daejeon, Republic of Korea).

Chemicals and Administration - Surfactin C sodium (purity $>98 \%$ ) was obtained from B \& C Biopharm (Yongin, Republic of Korea). Three groups of 30 rats (15 males and 15 female) received the surfactin $\mathrm{C}$ by intra-gastric gavages at the dose of 500,1000 and $2000 \mathrm{mg} / \mathrm{kg}$ body weight or distilled water (control) daily for 4 weeks. All rats were observed daily for physiological and behavioral changes. Body weight, water and food intake and weight gain were measured once a week. At the end of the study, all surviving animals were sacrificed for blood analysis, organ weighing, and gross and histopathological examination.

Blood Analysis — Prior to necropsy, surviving animals were fasted for $12 \mathrm{hr}$ and anesthetized with diethyl ether. Blood samples were collected from the caudal vena cava and carried out a blood analysis. The heparinized blood was used for a hematological study which included red blood cell count (RBC), hemoglobin concentration (Hb), hematocrit $(\mathrm{Ht})$, mean corpuscular volume (MCV), mean corpuscular hemoglobin $(\mathrm{MCH})$, mean corpuscular hemoglobin concentration (MCHC), platelets (Plt), white blood cell count (WBC) and white blood cell differential count. The non-heparinized blood was allowed to coagulate and then centrifuged to get serum. The obtained serum was assayed for aspartate aminotransferase (AST), alanine aminotransferase (ALT), alkaline phosphatase (ALP), blood urea nitrogen (BUN), lactate dehydrogenase (LDH), total protein, cholesterol and creatinine.

Histopathological Examination —_ Organs such as liver, lungs, heart, spleen, adrenals, kidneys, thyroid glands, testes and ovaries were removed and weighed at the time of necropsy. The organs fixed in $10 \%$ formalin for two days. Fixed tissue samples were embedded in paraffin and stained with hematoxillin-eosin dye. The pathological observations of all tissues were performed on gross and microscopic bases.

Statistics — Values were expressed as mean \pm S.D. The data were evaluated by the one-way analysis of variance (ANOVA) followed by Dunnett's multiple comparison test. A probability level of $p<0.05$ was considered as the level of statistical significance.

\section{RESULTS}

\section{Clinical Signs}

There was no surfactin C-related death at any dose in both sexes. No unusual changes in behavior and intoxication were observed during the 28 day period.

\section{Body Weight Gain, and Food and Water Con- sumption}

The highest dose of surfactin C significantly decreased body weight gains in both sexes from the control $(p<0.05$, Table 1$)$. There were no differences for food and water consumptions among all experiment groups.

\section{Blood Analysis}

There were no significant differences in the hematological parameters among the control and the experimental groups (data not shown). The effects of surfactin $\mathrm{C}$ on biochemical parameters are

Table 1. Body Weight Gain, and Food and Water Consumptions of Male and Female Rats Treated Orally with Surfactin C for 28 Days ${ }^{a)}$

\begin{tabular}{|c|c|c|c|c|c|c|c|c|}
\hline \multirow[t]{3}{*}{ Parameters } & \multicolumn{8}{|c|}{ "Surfactin C (mg/kg) } \\
\hline & \multicolumn{4}{|c|}{ Male } & \multicolumn{4}{|c|}{ Female } \\
\hline & 0 & 500 & 1000 & 2000 & 0 & 500 & 1000 & 2000 \\
\hline $\begin{array}{l}\text { Body weight gain } \\
\text { (g) }\end{array}$ & $106.3 \pm 6.6$ & $107.7 \pm 3.2$ & $106.9 \pm 7.1$ & $76.5 \pm 6.8^{*}$ & $75.8 \pm 8.4$ & $81.8 \pm 6.0$ & $78.3 \pm 9.5$ & $58.5 \pm 8.2^{*}$ \\
\hline $\begin{array}{l}\text { Food consumption } \\
\text { (g/day) }\end{array}$ & $19.9 \pm 4.3$ & $19.5 \pm 2.7$ & $20.4 \pm 3.6$ & $19.7 \pm 1.3$ & $16.0 \pm 3.1$ & $16.8 \pm 2.7$ & $17.9 \pm 5.2$ & $16.2 \pm 3.8$ \\
\hline $\begin{array}{l}\text { Water consumption } \\
(\mathrm{ml} / \text { day) }\end{array}$ & $30.4 \pm 7.5$ & $32.5 \pm 6.7$ & $33.1 \pm 8.9$ & $35.1 \pm 4.7$ & $29.73 \pm 4.3$ & $33.1 \pm 5.9$ & $34.4 \pm 7.8$ & $31.7 \pm 6.3$ \\
\hline
\end{tabular}

a) Each value is the mean \pm S.D. $(n=15)$. ${ }^{*}$ Significantly different from the control group, $p<0.05$. 
Table 2. Serum Biochemical Data of Male and Female Rats Treated with Surfactin C for 28 Days ${ }^{a}$ )

\begin{tabular}{|c|c|c|c|c|c|}
\hline \multirow[t]{3}{*}{ Parameters } & \multicolumn{5}{|c|}{ Purfactin C (mg/kg) } \\
\hline & \multicolumn{5}{|c|}{ Male } \\
\hline & \multicolumn{2}{|r|}{0} & 500 & 1000 & 2000 \\
\hline Alkaline phophatase & 164.3 & \pm 12.7 & $170.6 \pm 19.9$ & $292.6 \pm 29.0^{*}$ & $285.5 \pm 14.0^{*}$ \\
\hline Alanine transferase & 34.8 & \pm 4.9 & $40.0 \pm 4.5$ & $51.3 \pm 10.2^{*}$ & $53.3 \pm 9.5^{*}$ \\
\hline Aspartate transferase & 37.0 & \pm 5.6 & $41.9 \pm 6.0$ & $51.7 \pm 11.0^{*}$ & $50.3 \pm 9.2^{*}$ \\
\hline Cholesterol & 85.5 & \pm 7.2 & $88.8 \pm 4.1$ & $84.0 \pm 5.8$ & $85.8 \pm 8.2$ \\
\hline Creatinine & 0.50 & $0 \pm 0.08$ & $0.51 \pm 0.09$ & $0.46 \pm 0.05$ & $0.42 \pm 0.08$ \\
\hline Lactate dehydrogenase & 291.9 & \pm 54.8 & $285.7 \pm 32.2$ & $288.3 \pm 52.2$ & $281.3 \pm 43.1$ \\
\hline Total protein & 7.4 & \pm 0.2 & $7.0 \pm 0.5$ & $6.7 \pm 0.4$ & $7.0 \pm 0.5$ \\
\hline Blood urea nitrogen & 20.3 & \pm 1.7 & $21.3 \pm 2.1$ & $21.3 \pm 3.3$ & $16.8 \pm 4.1$ \\
\hline \multirow[t]{3}{*}{ Parameters } & \multicolumn{5}{|c|}{ Surfactin C (mg/kg) } \\
\hline & \multicolumn{5}{|c|}{ Female } \\
\hline & \multicolumn{2}{|r|}{0} & 500 & 1000 & 2000 \\
\hline Alkaline phophatase & 152.0 & \pm 14.9 & $166.0 \pm 19.9$ & $234.5 \pm 24.8^{*}$ & $250.0 \pm 11.3^{*}$ \\
\hline Alanine transferase & 28.8 & \pm 9.7 & $32.8 \pm 10.4$ & $41.6 \pm 9.5^{*}$ & $42.6 \pm 13.0^{*}$ \\
\hline Aspartate transferase & 37.7 & \pm 11.4 & $36.3 \pm 15.5$ & $50.8 \pm 15.7^{*}$ & $48.6 \pm 15.8^{*}$ \\
\hline Cholesterol & 93.0 & \pm 12.9 & $95.3 \pm 11.0$ & $91.8 \pm 9.6$ & $87.6 \pm 5.1$ \\
\hline Creatinine & 0.48 & $3 \pm 0.05$ & $0.49 \pm 0.07$ & $0.48 \pm 0.07$ & $0.48 \pm 0.04$ \\
\hline Lactate dehydrogenase & 260.2 & \pm 35.9 & $263.7 \pm 44.9$ & $269.4 \pm 27.6$ & $256.6 \pm 35.3$ \\
\hline Total protein & 7.3 & \pm 0.3 & $7.5 \pm 0.6$ & $7.5 \pm 0.7$ & $6.8 \pm 0.5$ \\
\hline Blood urea nitrogen & 17.0 & \pm 2.4 & $15.5 \pm 2.9$ & $16.8 \pm 2.7$ & $16.6 \pm 2.7$ \\
\hline
\end{tabular}

a) Each value is the mean \pm S.D. $(n=15)$. ${ }^{*}$ Significantly different from the control group, $p<0.05$.

Table 3. Relative Organ Weights (g/kg body weight) of Rats Treated with Surfactin C for 28 Days ${ }^{a}$ )

\begin{tabular}{|c|c|c|c|c|c|c|c|c|c|c|c|}
\hline \multirow{4}{*}{$\begin{array}{l}\text { Organs } \\
\text { Liver }\end{array}$} & \multicolumn{11}{|c|}{ Surfactin C $(\mathrm{mg} / \mathrm{kg})$} \\
\hline & \multicolumn{7}{|c|}{ Male } & \multicolumn{4}{|c|}{ Female } \\
\hline & \multicolumn{2}{|r|}{0} & \multicolumn{2}{|r|}{500} & \multicolumn{2}{|c|}{1000} & 2000 & 0 & 500 & 1000 & 2000 \\
\hline & 3.19 & \pm 0.39 & 3.25 & \pm 0.51 & 4.52 & $\pm 0.40^{*}$ & $3.96 \pm 0.22^{*}$ & $3.17 \pm 0.31$ & $3.27 \pm 0.34$ & $3.93 \pm 0.38^{*}$ & $3.65 \pm 0.25^{*}$ \\
\hline Spleen & 0.22 & \pm 0.04 & 0.22 & \pm 0.03 & 0.23 & \pm 0.02 & $0.24 \pm 0.05$ & $0.28 \pm 0.03$ & $0.29 \pm 0.04$ & $0.29 \pm 0.05$ & $0.27 \pm 0.06$ \\
\hline Kidi & 0.79 & \pm 0.08 & 0.91 & \pm 0.10 & 0.86 & \pm 0.09 & $0.84 \pm 0.08$ & $0.76 \pm 0.06$ & $0.87 \pm 0.06$ & $0.81 \pm 0.04$ & $0.77 \pm 0.03$ \\
\hline Adre & 0.014 & $4 \pm 0.002$ & 0.014 & $4 \pm 0.003$ & 0.018 & $8 \pm 0.011$ & $0.016 \pm 0.005$ & $0.024 \pm 0.009$ & $0.031 \pm 0.009$ & $0.031 \pm 0.004$ & $0.031 \pm 0.005$ \\
\hline Testes & 1.01 & \pm 0.05 & 0.97 & \pm 0.06 & 1.00 & \pm 0.08 & $1.10 \pm 0.09$ & - & - & - & - \\
\hline Ovaries & & - & & - & & - & 一 & $0.05 \pm 0.01$ & $0.04 \pm 0.01$ & $0.05 \pm 0.01$ & $0.06 \pm 0.01$ \\
\hline Heart & 0.35 & \pm 0.02 & 0.40 & \pm 0.05 & 0.39 & \pm 0.02 & $0.39 \pm 0.05$ & $0.38 \pm 0.05$ & $0.43 \pm 0.05$ & $0.40 \pm 0.04$ & $0.37 \pm 0.04$ \\
\hline Lung & 0.56 & \pm 0.04 & 0.65 & \pm 0.15 & 0.62 & \pm 0.11 & $0.58 \pm 0.05$ & $0.74 \pm 0.09$ & $0.68 \pm 0.11$ & $0.71 \pm 0.13$ & $0.60 \pm 0.09$ \\
\hline Thyroid & 0.008 & $8 \pm 0.002$ & 0.008 & $8 \pm 0.003$ & 0.007 & $7 \pm 0.004$ & $0.007 \pm 0.005$ & $0.009 \pm 0.002$ & $0.008 \pm 0.01$ & $0.007 \pm 0.004$ & $0.008 \pm 0.002$ \\
\hline Brain & 0.59 & \pm 0.02 & 0.59 & \pm 0.03 & 0.59 & \pm 0.03 & $0.61 \pm 0.06$ & $0.74 \pm 0.02$ & $0.74 \pm 0.05$ & $0.76 \pm 0.03$ & $0.70 \pm 0.05$ \\
\hline
\end{tabular}

a) Each value is the mean \pm S.D. $(n=15) .{ }^{*}$ Significantly different from the control group, $p<0.05$.

summarized in Table 2. ALT, AST and ALP levels were significantly increased in the groups administered with surfactin C 1000 or $2000 \mathrm{mg} / \mathrm{kg}$, comparing with the control $(p<0.05)$.

\section{Relative Organ Weights}

The relative organ weights are summarized in Table 3. Organ weights in all experimental groups were not significant differences comparing with that of control group, except the liver. The liver from animals administered with 1000 or $2000 \mathrm{mg} / \mathrm{kg}$ of sur- factin $\mathrm{C}$ showed significant increase in both sexes $(p<0.05)$.

\section{Histopathological Findings}

There were no evidences showing toxic effects of surfactin $\mathrm{C}$, except in liver tissues. Zonal necrosis of hepatocyte around the terminal hepatic vein was observed in the liver of animals administered with surfactin C 1000 or $2000 \mathrm{mg} / \mathrm{kg}$ (Fig. 1). However, $500 \mathrm{mg} / \mathrm{kg}$ of surfactin $\mathrm{C}$ did not show any toxicological alteration in the livers. 
(A)

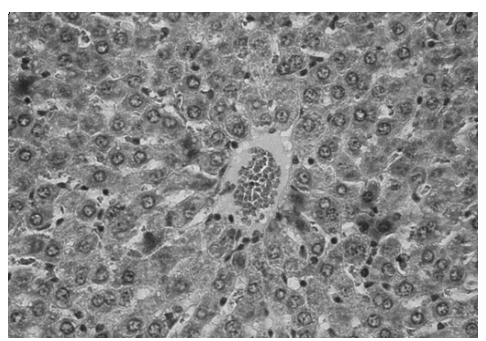

(C)

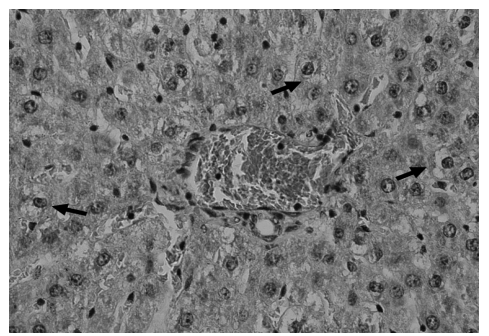

(B)

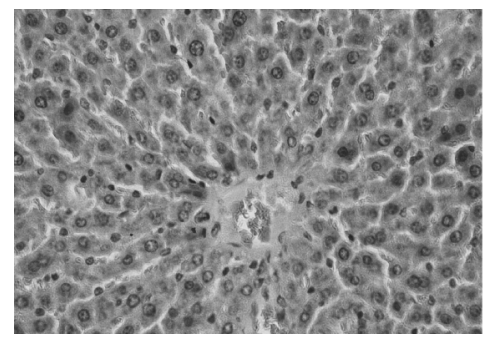

(D)

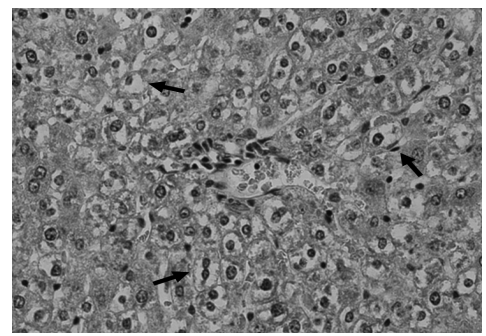

Fig. 1. Histopathological Alterations of Liver in Rats Orally Administered with Surfactin C during 4 Weeks (Hematoxylin and Eosin Staining, X 400)

(A) no treatment of surfctin C, (B) $500 \mathrm{mg} / \mathrm{kg}$ of surfactin C, (C) $1000 \mathrm{mg} / \mathrm{kg}$ of surfactin C, (D) $2000 \mathrm{mg} / \mathrm{kg}$ of surfactin C. Arrows show the hydropic necrosis of hepatocyte around the hepatic vein.

\section{DISCUSSION}

Surfactin C produced by Bacillus subtilis has a variety of biological activities, being generally known as a biosurfactant with low toxicity. ${ }^{4,16)}$ Kikuchi and Hasumi ${ }^{14)}$ reported that the i.v. $\mathrm{LD}_{50}$ of surfactin C was at $>100 \mathrm{mg} / \mathrm{kg}$ in mice. However, the evaluation of surfactin $C$ in repeated administration has not been reported. We performed the present study to establish a safety level of surfactin $\mathrm{C}$ through orally repeated administration during 28 days.

Oral administrations of surfactants are known to cause cytotoxicity in epithelial cells of the intestinal mucous membrane and to influence the rate of gastric emptying by increasing gastro-intestinal motility. ${ }^{17-19)}$ In this study, $2000 \mathrm{mg} / \mathrm{kg}$ of surfactin $\mathrm{C}$ decreased body weight gain despite normal food and water consumption. It is assumed that activities of surfactin $\mathrm{C}$ on the surface of gastro-intestinal tract lead to the altered absorption of nutrients and the injury of the mucosal membrane. Biological effects of surfactin $\mathrm{C}$ in the gastro-intestinal tract should be further clarified.

Antiplatelet and antithrombotic compounds induce systemic and/or cerebral haemorrhages as the compound-related adverse effect. ${ }^{20,21)}$ Sufactin C was found to have fibrinolytic, anticoaguant and an- tithrombotic activities through inhibition of platelet aggregation in vitro. ${ }^{8,12)}$ These findings suggest that surfactin $\mathrm{C}$ may have potential toxicity in the hematopoietic system due to its anti-coagulant effects. However, surfactin C-related toxicities in hematological parameters and histopathological observation of hematopoietic organs were not found in our study.

However, repeated administration of surfactin C 1000 or $2000 \mathrm{mg} / \mathrm{kg}$ significantly increased serum ALT, AST and ALP levels, which indicated the necrosis of hepatocyte. The relative liver weights in animals treated with the same dosages of surfactin $\mathrm{C}$ also showed significant increases in comparison with the control $(p<0.05)$. In histopathological study, the hydropic necrosis of hepatocyte was also occurred in a dose-dependent manner. These results indicate that above $1000 \mathrm{mg} / \mathrm{kg}$ of surfactin C can cause structural and functional alterations in the liver tissue.

In conclusion, $500 \mathrm{mg} / \mathrm{kg}$ of surfactin $\mathrm{C}$ did not show any toxic effects during the experimental period. In this study, NOAEL of surfactin $\mathrm{C}$ can be suggested the $500 \mathrm{mg} / \mathrm{kg}$. Further studies for the chronic toxicity of surfactin $\mathrm{C}$ are needed for its practical applications in the food, cosmetic and medical fields. 
Acknowledgements This work was supported by a grant (code \#20050301-034-427-115) from BioGreen 21 Program, Rural Development Administration, Republic of Korea.

\section{REFERENCES}

1) Kosaric, N. (1992) Biosurfactants in industry. Pure Appl. Chem., 64, 1731-1737.

2) Scott, M. J. and Jones, M. N. (2000) The biodegradation of surfactants in the environment. Biochim. Biophy. Acta, 1508, 235-251.

3) Banat, I. M., Makkar, R. S. and Cameotra, S. S. (2000) Potential commercial applications of microbial surfactants. Appl. Microbiol. Biotechnol., 53, 495-508.

4) Cameotra, S. S. and Makkar, R. S. (2004) Recent applications of biosurfactants as biological and immunological molecules. Curr. Opin. Microbiol., 7, 262-266.

5) Vollenbroich, D., Pauli, G., Ozel, M. and Vater, J. (1997) Antimycoplasma properties and application in cell culture of surfactin, a lipopeptide antibiotic from Bacillus subtilis. Appl. Environ. Microbiol., 63, 44-49.

6) Ahimou, F., Jacques, P. and Deleu, M. (2000) Surfactin and iturin A effects on Bacillus subtilis surface hydrophobicity. Enzyme Microb. Technol., 27, 749-754.

7) Carrillo, C., Teruel, J. A., Aranda, F. J. and Ortiz, A. (2003) Molecular mechanism of membrane permeabilization by the peptide antibiotic surfactin. Biochim. Biophys. Acta, 1611, 91-97.

8) Bernheimer, A. W. and Avigad, L. S. (1970) Nature and properties of a cytolytic agent produced by Bacillus subtilis. J. Gen. Microbiol., 61, 361-369.

9) Kameda, Y., Oira, S., Matsui, K., Kanatomo, S. and Hase, T. (1974) Antitumor activity of bacillus natto. $\mathrm{V}$. Isolation and characterization of surfactin in the culture medium of Bacillus natto KMD 2311. Chem. Pharm. Bull. (Tokyo), 22, 938-944.

10) Kim, K., Jung, S. Y., Lee, D. K., Jung, J. K., Park, J. K., Kim, D. K. and Lee, C. H. (1998) Suppression of inflammatory responses by surfactin, a selective inhibitor of platelet cytosolic phospholipase A2. Biochem. Pharmacol., 55, 975-985.
11) Oka, K., Hirano, T., Homma, M., Ishii, H., Murakami, K., Mogami, S., Motizuki, A., Morita, H., Takeya, K. and Itokawa, H. (1993) Satisfactory separation and MS-MS spectrometry of six surfactins isolated from Bacillus subtilis natto. Chem. Pharm. Bull. (Tokyo), 41, 1000-1002.

12) Rodrigues, L., Banat, I. M., Teixeira, J. and Oliveira, R. (2006) Biosurfactants: potential applications in medicine. J. Antimicrob. Chemother, 57, 609-618.

13) Lim, J. H., Park, B. K., Kim, M. S., Hwang, M. H., Rhee, M. H., Park, S. C. and Yun, H. I. (2005) The anti-thrombotic activity of surfactins. J. Vet. Sci., 6 , 353-355.

14) Kikuchi, T. and Hasumi, K. (2002) Enhancement of plasminogen activation by surfactin C: augmentation of fibrinolysis in vitro and in vivo. Biochim. Biophys. Acta, 1596, 234-245.

15) Hwang, Y. H., Park, B. K., Lim, J. H., Kim, M. S., Park, S. C., Hwang, M. H. and Yun, H. I. (2007) Lipopolysaccharide-binding and neutralizing activities of surfactin $\mathrm{C}$ in experimental models of septic shock. Eur. J. Pharmcol., 556, 166-171.

16) Desai, J. D. and Banat, I. M. (1997) Microbial production of surfactants and their commercial potential. Microbiol. Mol. Biol. Rev., 61, 47-64.

17) Moore, J. D., Zatzman, M. L., Overack, D. E. and Platner, W. S. (1971) The effects of synthetic surfactants on intestinal permeability to glucose in vitro. Exp. Biol. Med., 137, 1135-1139.

18) Isomaa, B. (1975) Absorption, distribution and excretion of $\left[{ }^{14-} \mathrm{C}\right] \mathrm{CTAB}$, a quarternary ammonium surfactant, in the rat. Food Cosmet. Toxicol., 13, 231-237.

19) Cserhati, T. (1995) Alkyl ethoxylated and alkylphenol ethoxylated nonionic surfactants: interaction with bioactive compounds and biological effects. Environ. health perspect., 103, 358-364.

20) Diez-Tejedor, E., Alonso de Lecinana, M., Counsell, C. and Sandercock, P. (1995) Antithrombotic treatment in acute ischemia stroke. Neurología, 10, 4854.

21) Gámez, R., Mas, R., Noa, M., Menéndez, R., Alemán, C., Acosta, P., García, H., Hernández, C., Amor, A., Pérez, J. and Goicochea, E. (2000) Acute and oral subchronic toxicity of D-003 in rats. Toxicol. Lett., 118, 31-41. 